\title{
Some aspects of the problem of energy efficiency and energy saving in Russia
}

\author{
Aleksandr Aleksandrovich Nikiforov ${ }^{1}$, Vera Dmitrievna Nikiforova ${ }^{2}$, and Mark \\ Mikhailovich Khaikin ${ }^{1}$ \\ ${ }^{1}$ St. Petersburg Mining University, St. Petersburg, Russia \\ ${ }^{2}$ St. Petersburg State University of Industrial Technologies and Design, St. Petersburg, Russia
}

\begin{abstract}
The article is devoted to the analysis of the current state of the Russian energy sector in the context of the gradual reform of the industry. The authors focused their attention on topical issues of energy efficiency and energy saving, using the methodology of space-time and comparative approaches to study. The following are highlighted as topical study tasks: 1) identification of trends and factors of changes in energy consumption of traditional and renewable energy sources, achievement of energy efficiency in Russia and abroad; 2) determination of the potential for investment attractiveness of traditional and renewable Russian energy; 3) substantiation of directions for increasing the level of energy efficiency and energy saving by reducing investment risks in the industry, improving the policy of tariff regulation, gradually eliminating cross-subsidizing, completing the consolidation processes in the power grid market, creating conditions for development of small-scale energy. In accordance with the tasks set, domestic and foreign scientific study in the field of energy conservation and energy efficiency, data from industry statistics, Rosstat are summarized. The results obtained are an intermediate stage in the study of the raised problem and may require clarification.
\end{abstract}

\section{Introduction}

Energy forms the basis for the world civilizational development characterized by cyclicality throughout the history of mankind. The regularity of cyclicality is the change of civilizations, the emergence of new goals, meanings and potentials of socio-economic development. [1] At the same time, spatio-temporal fractality can be traced, which manifests itself, first of all, in the trends and commonality of the evolution of civilizations. As criteria for periodization of the stages of development of the world fuel and energy complex, the following can be specified: (1) general and per capita growth / decrease in energy consumption; (2) an increase in the energy intensity of the gross domestic product; (3) the curtailment of energy-intensive industries; (4) gradual change of the dominant energy resource, etc.

While possessing the property of technological unity in the world space, today the fuel and energy complex makes the subjects of the energy market interdependent. The postindustrial economy of developed countries demonstrates a gradual transition from nonrenewable to renewable energy, an orientation towards energy-saving and energy-efficient technologies. In developing countries that are still at the stage of industrial development, 
there is an increase in energy consumption. As world statistics show, in general, world energy consumption is growing for all types of raw materials, mainly due to countries such as the United States, China, India. Wherein, energy consumption per capita is also increased. According to some calculations, in recent years, for every $1 \%$ of population growth, on average, there has been an increase in energy consumption by $1.5 \%$. Per capita energy consumption will decrease in almost all developed countries. [2]

\section{Materials and Methods}

It shall be noted that energy consumption indicators are largely determined by demographic factors: the dynamics of population growth/decrease, urbanization processes (mainly in developing countries), an increase in the proportion of the population of retirement age, and etc. However, it would be a mistake to assume that only demographic factors affect energy consumption. Such economic factors as the price of energy resources, GDP growth rates, energy conservation and energy efficiency policies, economic crisis, and etc., can have a certain influence on it. Analysis of the structure of energy consumption of non-renewable energy sources indicates that about $40 \%$ is accounted for by oil, $31.6 \%$ - by natural gas, 24.6 $\%$ - by coal and about $4 \%$ - by nuclear energy. The threat of depletion of the reserves of these sources increases the intensity of the struggle and conflicts over energy resources, especially from the United States and the Western countries, highlighting the country's energy safety policy [3].

Among renewable sources, the main share falls on hydropower (43\%), and wind energy (26\%). Europe, North America, as well as Russia and Turkey are actively working in the direction of increasing renewable energy capacities. Above average growth rates of renewable sources in the production of electricity are noted in countries with significant reserves of water resources (China, Russia, Sweden, Norway, Brazil, Japan). It can be assumed that further strengthening of the geographic factor of renewable energy shall be expected. In the global energy balance, the share of renewable energy sources at the moment is more than $28 \%$, and for individual countries of the world this indicator has the following values: $39 \%$ in the energy balance of the European Union countries, $28 \%$ - in China, $23 \%$ - in India, 20 \% - USA, Russia, Japan. [4]

As you know, Russia has a very high natural potential for development of renewable energy. However, the country is also interested in maintaining the existing rates of growth in the production and supply of oil, gas, coal, nuclear energy, since its economy is heavily dependent on the export of hydrocarbon raw materials. The high level of diversification of modern world energy allows maintaining high rates of traditional energy and not allocating the basic energy carrier in the energy balance. In developing countries (Russia, China, India), renewable energy is an element of the diversification of the energy balance, while they maintain high rates of industrial development of the energy sector [5].

According to the World Bank, Russia has been holding a leading position in the production of electric power for a number of years (fourth in the world); at the same time, in terms of GDP per capita (in terms of purchasing power parity), it ranks 50th, in terms of electricity consumption per capita - 28th place (2020). A distinctive feature of 2020 was a significant decrease in the consumption of non-renewable energy sources (by $4.4 \%$ ) in the global economy as a whole against the background of an increase in the consumption of renewable energy sources. Russia was among the leaders of the countries where the largest drop in energy consumption of resources was noted. As a regularity of the last decade, we can note the gap between GDP growth and the dynamics of energy consumption mainly in developed countries (Germany, Great Britain, USA, Japan) and China, where the volume of primary energy consumption has decreased or stabilized. For the Russian Federation, the analysis revealed the outstripping growth of energy consumption in comparison with GDP, 
which demonstrates the extensive direction of development of its economy. Up to $26 \%$ of the total energy consumption falls on the electric power sector, $22 \%$ - on the manufacturing industry, $17 \%$ - on the population, $16 \%$ - on transport; the smallest consumption among these groups of consumers is observed in budgetary organizations.

\section{Results and Discussion}

The synchronous growth of these indicators, characteristic of the period before the $1970 \mathrm{~s}$, today cannot be evidence of sufficient energy efficiency in use of resources. Forecasts of a decrease in the energy intensity of Russia's GDP for 2009-2020 for $40 \%$ were fulfilled by less than $33 \%$ (the reduction in energy intensity was only $13 \%$ ). Of course, the cold climate in a large part of its territory, long distances and the associated high transport and infrastructure costs have a significant impact on energy consumption and energy intensity in the country. However, if a comparison is made with a country similar in climatic conditions, for example, with Canada, then the excess of the energy intensity indicator is $17 \%$, and in terms of the "specific energy consumption in the residential sector" indicator for individual regions may differ by a factor of 3. [6]

It can be assumed that in Russia there is still sufficient potential for increasing the efficiency of energy use not only of primary, but also of secondary forms. According to World Bank estimates, our country can achieve savings of up to $45 \%$ of total primary energy consumption. To move in the direction of global trends in energy efficiency, the following is imperative: (1) a more significant increase in investment in energy conservation; (2) an increase in the number of high-tech industries and introduction of advanced technologies (steam and gas installations, combined generation of electricity and heat, etc.); (3) reduction in the share of exports of first-stage products, especially energy-intensive ones; (4) widespread implementation of energy management and lean manufacturing standards; (5) introduction of energy saving standards in the field of housing and communal services; (6) to abandon all-inclusive tariff policy in the field of electricity production and distribution; (7) to expand tax incentives and measures to stimulate energy efficiency and energy conservation in energy-intensive sectors of the economy; (8) broader information support for state energy efficiency programs; (9) increasing the literacy of the population in the field of energy conservation; (10) a decrease in the level of market concentration, especially in the field of electric power transmission, and other measures. Although much has already been done in this direction, more remains to be done.

Within the framework of this article, the authors understand energy efficiency as the ratio between the beneficial effect (result) obtained from the use of fuel and energy resources and the cost of this resource for its production. Energy saving is understood as a set of measures (organizational and legal, technical and economic, etc.) aimed at the economical and rational use of non-renewable fuel and energy resources and at involvement of renewable energy sources in the economy while achieving the target level of beneficial effect from their use.

According to Rosstat, in 2018, investments in energy saving increased by $26 \%$ compared to 2017 and 2016, but at the same time they did not exceed $0.2 \%$ of the Russian Federation's GDP and were insufficient for structural changes. If we consider this indicator in the context of the regions of the country, then for the constituent entities of the Russian Federation, the spread is about 300 times. Moreover, the coronavirus pandemic had a strong impact on the pace and scale of investments in the Russian fuel and energy complex: design work was cut, investments were postponed, which led to a disruption in supply chains in a number of industries. In its turn, the fall in oil prices intensified the negative impact on the investment activity of the energy sector. Wherein, it shall be noted that despite the general decrease in investments in the electric power industry in some areas, their growth is noted due to measures of state support for renewable energy sources, modernization of thermal generation, 
small-scale energy projects, construction of new nuclear power plants and hydroelectric power plants (2020). The regional aspect of investment, which is characterized by the modernization of distributed power generation in remote and isolated regions of the Arctic and the Far East, the development of small generation in the Urals is of particular note [7].

In Russia, about $50 \%$ of fuel and energy resources are consumed in industrial units for the direct use of these resources, the rest - in the electric power industry for the production of electricity and heat. The high level of depreciation of fixed assets in the fuel and energy complex largely determines the high costs of energy production (see Table 1) which affect the cost of industrial products. Structural analysis of the depreciation of fixed assets by type of economic activity "provision of electricity, gas and steam, air conditioning" showed that the highest level of depreciation (more than $64 \%$ ) falls on vehicles, about $50 \%$ - on machinery and equipment, the share of which in the total volume of fixed assets of organizations of this type of activity reaches approx. $50 \%$.

Table 1. Depreciation rate of fixed assets of the Russian Federation at the end of the year by type of economic activity, \% (according to Rosstat data)

\begin{tabular}{|l|c|c|c|c|}
\hline Economic activities & $\mathbf{2 0 1 7}$ & $\mathbf{2 0 1 8}$ & $\mathbf{2 0 1 9}$ & $\mathbf{2 0 2 0}$ \\
\hline $\begin{array}{l}\text { For all types of economic } \\
\text { activities }\end{array}$ & 47.3 & 46.6 & 37.8 & 38.0 \\
\hline Including: & & & & \\
\hline - mining & 57.7 & 55.6 & 55.9 & 55.9 \\
\hline $\begin{array}{l}\text { - provision of electricity, } \\
\text { gas and steam, air } \\
\text { conditioning }\end{array}$ & 45.2 & 45.6 & 45.7 & 45.7 \\
\hline
\end{tabular}

Use of outdated machinery and equipment, technologies leads to significant technological losses, excessive consumption of equivalent fuel, and an increase in the cost of electricity production. According to some estimates, the efficiency of all fuel and energy resources in the country's economy can reach $40 \%$.

The current situation with energy efficiency and energy saving is quite alarming and requires an improved approach to the system of regulation of the electric power industry and the entire fuel and energy complex. Wherein, it is important to carry out an objective expert examination of organizations, which shall be greatly facilitated by an energy audit. However, as practice shows, the energy audit has not yet coped with the task set before it. Often it is carried out formally, auditors give various assessments regarding the state of energy efficiency and energy saving at enterprises. The lack of a complete and real picture of the state of the energy industry, unified methods for evaluating innovative projects creates additional risks for private investors, whose share has been decreasing in recent years. [8]

High risks for investors also arise in connection with the policy of tariff regulation. The geography of the electricity market from the point of view of this issue makes it possible to single out several zones, among which there are non-price zones (northern regions, the Kaliningrad region, the Far East). The low level of infrastructure and its isolation do not allow the transition to market mechanisms in non-price zones. For investments, a freer field is formed in the sales sector, however, systematic non-payments by consumers for the supplied electricity and losses make this area unattractive for private investors, and also create problems for development of distribution networks closely related to sales in the supply chain links. Private investors' investments in grid and distribution assets are limited by the territorial monopoly position of operating companies. The government's consistent policy to curb tariffs on the basis of the inflation minus principle does not stimulate the attraction of private investors. The current situation favors the use of bank loans to a greater extent, rather than private investment, under guarantees laid down in tariff regulation. Therefore, the state and consumers become the main investors. 
It shall be noted that the policy of low prices for energy resources can give competitive advantages to the domestic industry, but only in the short term, and not in the long term, since prices will not be able to provide a return on investment in new technologies of energy organizations. Moreover, as the analysis has shown, the containment of energy prices, if it had, an insignificant effect on the cost of expenses in most energy-intensive industries. Wherein, it is important to consider that the fuel and energy complex is closely related to other sectors of the economy as a customer and underinvestment in it can negatively affect the economic development of such industries as construction, mechanical engineering, and etc. With regard to the population, it is also necessary to change the policy of general containment of tariffs to expand the practice of targeted support based on the level of income. At the moment, only $15 \%$ of the subjects of the federation use a differentiated approach to the pricing of energy resources for the population; differentiation is carried out not according to income, but on the basis of "rural population", "urban population", equipment of the house with electric stoves. In $7 \%$ of regions, a social norm of energy consumption has been established.

No less problem for the fuel and energy complex today is cross-subsidization, which arose in Russia in the early $90 \mathrm{~s}$ of the last century as a measure of social protection of the population, financed by industrial enterprises. Since 2013, cross-subsidization has been used to support and develop the field of renewable energy sources, and since 2017 - to compensate for the costs of utilization programs for solid utility costs (intersectoral cross-subsidization). According to some estimates, the volume of cross-subsidization in distribution networks alone reaches 240 billion rubles per year, and in general in the power industry - about 368 billion rubles. [9] Given the growth in electricity consumption, we can expect a natural increase in the volume of cross-subsidies. Wherein, the problem lies not only in the fact that enterprises have to pay for low tariffs for the population and curtail their investment programs, but also that the practice of cross-subsidization makes it difficult to obtain complete and transparent information about the structure of the established tariffs for different groups of consumers.

The measures taken by the state to reduce the volume of cross-subsidization are designed for a long period. [10] These measures are ultimately aimed at bringing tariffs for the population to an economically viable level, which can be partly facilitated by the "inflation plus" policy. Introduction of Rab-regulation aimed at stimulating investment activity in the power grid sector through the application of the cost-plus method for a long period, in conditions of economic instability (due to crises, pandemic) does not allow many companies to receive guaranteed income. Those companies that switch to long-term indexing (instead of the Rab method) have restrictions in the investment tariff in the amount of $12 \%$ of the required gross revenue. According to the calculations of the Ministry of Economic Development, the elimination of cross-subsidization will require approximately 402 billion rubles budgetary funds annually, however, there are no sources for financing this activity in the current situation.

The reform of the fuel and energy complex also includes implementation of the policy of consolidation of the power grid complex, which is designed to reduce the financial burden on the consumer by reducing scattered small grid enterprises, eliminating ineffective costs, as well as duplicating functions, combining sources of financing for all types of activities (operating, financial and investment). As a result of the first stage of consolidation measures, the number of territorial grid organizations decreased by $44.2 \%$ compared to 2014 and amounted to 1,623, which increased the degree of market concentration. However, despite a significant reduction in the number of local grid operators, consumer spending has decreased insignificantly. Wherein, negative consequences arose due to emergence of "ownerless grids" due to the lack of procedures for transfer of electric grids by organizations deprived of the local grid operator status to management of qualified organizations. 
Completion of the consolidation process is constrained by gaps in the legal framework. It is important at the legislative level to determine the legal status of the owners of power grids that have been deprived of the local grid operator status, as well as to determine the procedure for reimbursing the costs of servicing power grid facilities that do not have the local grid operator status. It is clear that the local grid operator incurs significant costs for consolidation of power grid assets, which it would like to compensate in the tariff. From the point of view of the Federal Antimonopoly Service of the Russian Federation, inclusion of these costs in the tariff is inexpedient, since it will lead to a significant and unjustified increase in tariffs; therefore, it is offered to use, first of all, owners' funds and other non-tariff sources. A number of experts believe that the cost of consolidation can be offset by the tariff, if the reliability and quality of the power supply is improved. [11] Ultimately, effectiveness of consolidation from the standpoint of tariff consequences will largely depend on the forms of its implementation: purchase, lease, leasing, gratuitous receipt of power grid facilities, concession, establishment of a joint venture, and etc.

\section{Conclusion}

To a certain extent, small-scale energy is capable of solving the problems of reforming the fuel and energy complex, its adaptation to the market with a lack of large investors, as well as the problems of energy efficiency and energy conservation. Its production capacities are closer to the consumer, losses during power transmission are minimal, higher efficiency; it does not require significant investments compared to large energy systems and does not have long payback periods, which reduces investment risk. Moreover, small-scale energy entities can offer a relatively low price for energy resources due to exclusion of network and sales surcharges from the tariff. However, small-scale energy cannot guarantee the reliability and consistency of energy consumption by analogy with centralized energy systems. It is important to understand that small-scale energy is not a big competitor; it is mainly represented in the regions of the Far North, in the Far East, in Siberia, where it makes up for the lack of electricity and heat through the Unified Energy System of Russia.

In the EU countries, small-scale energy (decentralized generation) accounts for up to $50 \%$ of all electricity generated in the country. In our country, this figure does not exceed $10 \%$; [12] at the same time, the reasons for its development in Russia are different than in European countries. If, for example, in Germany the main reasons are transition from nonrenewable to renewable energy sources and the desire for independence from energy imports, then in our country the development of small-scale energy is mainly associated with the high price of energy resources, as well as the impossibility of obtaining a network resource due to remoteness of the source. In the regulatory documents of the Russian Federation, small energy is usually understood as power plants with a capacity of up to $25 \mathrm{MW}$; limiting the production capacity limit allows small generation facilities to carry out sales in the retail market and not enter the wholesale market, where activities are associated with certain difficulties for them. Wherein, it shall be noted that at the legislative level, the small power industry does not receive proper support. Its subjects face a number of legislative obstacles when they want to sell electricity to the wholesale network and are often forced to transfer surplus free of charge. Wherein, some experts express concern that development of small generation can undermine the financial base of the country's single power system, if there is a massive consumer shift to decentralized energy. 


\section{References}

1. V. L. Ulanov, E. Yu. Ulanova, Notes of the Mining Institute, 238, 474 (2019)

2. Energy Bulletin, 85 (2020)

3. N. Kirsanova, O. Lenkovets, M. Hafeez, J. of Marine Science and Engineering, 8(12), 1 (2020)

4. Key trends in energy consumption in the XXI century, https://yearbook.enerdata.ru

5. Modern technologies and economics in energy (MTEE-2020), Materials of the international scientific and practical conference (2020)

6. V. S. Litvinenko, P. S. Tsvetkov, M. V. Dvoinikov, G. V. Buslaev, Notes of the Mining Institute, 244, 428 (2020)

7. L. Makhova, Academy of Accounting and Financial Studies J., 22(3), 1 (2018)

8. P.A. Kruglikov, Yu.V. Smolkin, Innovatics and expertise, 1(16), 167 (2016)

9. Recommendations of the round table on the topic "Issues of cross-subsidization in the electric power industry, its impact on the development of the industry and the country's economy, measures to minimize it", http://komitet2-13.km.duma.gov.ru

10. S.N. Osipov, V.M. Pilipenko, Proceedings of higher educational institutions and energy associations of the CIS", 2 (2015)

11. Expert and analytical note on the topic: "Consolidation of the power grid complex of the Russian Federation: legal framework and basic mechanisms", https://em.ranepa.ru

12. Small-scale energy in Russia: advantages and practical problems, https://advocates.su 